\title{
KEPUASAN, LOYALITAS KONSUMEN DAN STRATEGI PENGEMBANGAN AGROINDUSTRI KERUPUK BAWANG DI KOTA BANDAR LAMPUNG
}

\author{
(Satisfaction, Consumers Loyalty, and Strategy Development of Onion Cracker Agroindustry \\ in Bandar Lampung City)
}

Nurul Fajri Indah Lestari, Dyah Aring Hepiana Lestari, Ani Suryani

Jurusan Agribisnis, Fakultas Pertanian, Universitas Lampung, Jl. Prof. Dr. Soemantri Brojonegoro No. 1 Bandar Lampung 35141, e-mail: dyah.aring@fp.unila.ac.id

\begin{abstract}
This research aims to analyze the level of satisfaction and loyalty of consumers'of onion crackers and build strategies on the development of onion creackers agroindustry in Bandar Lampung city. This research is a case study. The samples are stakeholders from agroindustry, government officer, employees, and consumers of onion crackers. Technique sampling for consumers is snowballing. The methods of data analysis used are Customer Satisfaction Index analysis(CSI) analysis, SWOT analysis and Quantitive Strategic Planing Matrix analysis (QSPM). The results of this research showed that onion crackers consumers were loyal customers with high levels of satisfaction $(C S I=71.04 \%)$ and on the loyalty pyramid consumers were categorized as loyal, because $63.33 \%$ of them were committed buyers. For strategies combination IFE value was 2.686 and EFE was 2.645. In the internal and external matrix the position of the business was in quadrant $V$, meaning that agroindustry were in the growth phase. Based on QSPM analysis, the recommended strategies were to increase the production amount especially in dry season in order to meet consumer demand in rainy season by implementing the provided production machines which were owned by the agroindustry.
\end{abstract}

Key words: consumer, loyalty, onion crackers, statisfaction, strategy.

\section{PENDAHULUAN}

Diversifikasi pangan adalah program yang dilakukan agar masyarakat tidak terpaku pada satu jenis makanan pokok saja dan terdorong juga untuk mengonsumsi bahan pangan lainnya sebagai pengganti makanan pokok (beras) yang selama ini dikonsumsi. Pandangan masyarakat yang menganggap beras adalah sumber energi utama perlu dihapuskan dengan mencari alternatif pangan pengganti beras. Bahan makanan yang dapat menjadi pengganti beras adalah bahan makanan yang memiliki kandungan gizi yang serupa atau lebih tinggi dari beras. Salah satu bahan makanan yang memiliki kandungan gizi yang serupa adalah ubi kayu yang berasal dari golongan umbi-umbian.

BPS (2015) menyatakan bahwa Provinsi Lampung merupakan provinsi penghasil ubi kayu nomor satu di Indonesia. Ubi kayu dapat menjadi pilihan untuk dijadikan pendamping pangan pokok program diversifikasi pangan. Jumlah produksi ubi kayu yang tinggi dapat mendukung keberhasilan program diversifikasi pangan. Masyarakat Provinsi Lampung saat ini sedang menjalankan program diversifikasi pangan melalui proses pengolahan ubi kayu menjadi berbagai macam bentuk olahan makanan, salah satunya adalah kerupuk. Kerupuk merupakan jenis makanan kering dengan bahan baku utama tepung tapioka yang berasal dari pengolahan ubi kayu. Salah satu kerupuk yang sering dikonsumsi masyarakat adalah kerupuk bawang. Kerupuk bawang merupakan hasil olahan antara tepung tapioka, ikan, dan bawang yang dicampur menjadi satu kesatuan. Proses pengolahan kerupuk bawang tersebut dilakukan dalam sebuah usaha agroindustri.

Kota Bandar Lampung merupakan kota di Provinsi Lampung yang banyak memiliki usaha pengolahan ubi kayu menjadi kerupuk. Salah satu agroindustri di Bandar Lampung adalah Agroindustri Kerupuk Bawang Winda Putri (KBWP). Agroindustri ini merupakan agroindustri yang memproduksi kerupuk bawang dan berlokasi di Kecamatan Tanjung Senang Kota Bandar Lampung. Agroindustri kerupuk bawang ini tergolong ke dalam usaha mikro, karena omzet yang diterima agroindustri ini masih kurang dari Rp50.000.000,00. Agroindustri ini mampu memproduksi kerupuk bawang hingga 7 kuintal per satu kali produksi, namun belum dapat memaksimalkan keadaan lingkungan internal dan eksternal. Kondisi ini menunjukkan bahwa agroindustri masih berupaya untuk meningkatkan 
perkembangan usahanya. Proses pengembangan agroindustri tidak terlepas dari konsumen atau pelanggan. Banyak sedikitnya pelanggan dari suatu agroindustri dapat mempengaruhi tingkat keuntungan dari suatu agroindustri. Oleh karena itu, pelanggan harus puas dan setia terhadap kerupuk bawang. Untuk mengetahuinya perlu dilakukan analisis tingkat kepuasan dan loyalitas konsumen. Selanjutnya, agroindustri ini harus menyusun strategi yang tepat. Oleh karena itu, tujuan penelitian ini mengidentifikasi tingkat kepuasan konsumen, mengidentifikasi tingkat loyalitas konsumen, dan menyusun strategi pengembangan bagi agroindustri.

\section{METODE PENELITIAN}

Metode penelitian ini adalah studi kasus di agroindustri KBWP yang dipilih secara purposive, karena produksi kerupuk bawang tergolong tinggi, yaitu $500 \mathrm{~kg}$ sampai $700 \mathrm{~kg}$ per produksi. Jumlah responden (konsumen) kerupuk bawang merujuk Supranto (2006), bahwa sampel penelitian yang lebih besar dari 30 dan kurang dari 500 adalah tepat untuk kebanyakan penelitian. Berdasarkan uraian tersebut, maka peneliti mengambil sampel konsumen sebanyak 60 responden. Responden untuk strategi pengembangan sebanyak 9 orang yang terdiri dari 1 orang pemilik agroindustri, satu orang karyawan agroindustri, 1 orang Dinas Perindustrian, dan 6 orang konsumen kerupuk bawang. Penentuan responden (konsumen) agroindustri adalah secara snowballing. Data yang digunakan dalam penelitian terdiri dari data primer dan data sekunder. Pengumpulan data dilakukan pada bulan Februari-Mei 2018.

Metode yang digunakan untuk menganalisis tingkat kepuasan konsumen adalah metode Customer Satisfaction Index (CSI) dan untuk menganalisis tingkat loyalitas konsumen digunakan piramida loyalitas. Untuk menyusun strategi pengembangan digunakan metode analisis SWOT dan Quantitive Strategic Planning Matrix (QSPM). Analisis kepuasan dan loyalitas diukur menggunakan kuisioner dengan skala likert yang lebih dahulu diuji validitas dan reliabilitas. Uji ini dilakukan terhadap 9 atribut yaitu rasa, harga, ukuran kemasan, tekstur kerupuk bawang, kemudahan memperoleh produk, warna, bentuk, aroma kerupuk bawang dan kandungan gizi, dari 30 responden. Hasil uji menunjukkan atribut yang digunakan sebagai alat ukur kepuasan dan loyalitas konsumen secara tepat dan cermat dapat digunakan (valid dan reliabel). Hal ini dikarenakan berdasarkan nilai extraction yang didapatkan berada di atas 0,20. Uji reliabilitas kepuasan menunjukkan nilai yang lebih besar dari 0,60 yaitu 0,811 dan 0,808 dan untuk loyalitas sebesar 0,739 berarti alat ukur yang digunakan reliabel (Nathael dan Sufren 2013).

Customer Satisfaction Index (CSI) atau indeks kepuasan konsumen adalah sebuah angka yang menyatakan seberapa besar tingkat kepuasan konsumen akan produk tertentu (Santoso 2006). CSI digunakan untuk mengetahui tingkat kepuasan pelanggan secara keseluruhan dengan memperhatikan tingkat kepentingan dari atributatribut suatu produk atau jasa. Nilai maksimum untuk CSI adalah 100\% dengan rentang nilai menurut Supranto (2006) yakni sangat puas (81\%$100 \%)$, puas (66\%-80\%), cukup puas $(51 \%-65 \%)$, kurang puas (35\%-50\%), dan tidak puas (0\%$34 \%$ ). Berikut merupakan rumus perhitungan CSI.

$\mathrm{CSI}=\frac{(\mathrm{T})}{5(\mathrm{Y})} \times 100 \%$

\section{Keterangan :}

CSI = Customer Satisfaction Index

(T) $\quad=$ Total seluruh skor

(Y) = Total seluruh nilai harapan (kepentingan)

$5=$ Nilai maksimum yang digunakan dalam skala pengukuran

Analisis tingkat loyalitas diukur menggunakan piramida loyalitas yang memiliki lima tingkatan yang terdiri dari switcher buyer, habitual buyer, satisfied buyer, liking the brand, dan committed buyer. Konsumen dikatakan loyal, apabila nilai committed buyer lebih besar dibandingkan nilai switcher buyer.

Analisis SWOT digunakan untuk menganalisis faktor-faktor internal dan eksternal yang terdiri dari kekuatan, kelemahan, peluang dan ancaman yaitu tentang bagaimana memaksimalkan kekuatan dan peluang, serta meminimalkan kelemahan serta acaman dan merencanakan strategi yang sepatutnya diambil pada masa mendatang (Rangkuti 2005). Hal yang harus dilakukan adalah mendaftarkan item-item faktor strategi internal (IFAS) dan eksternal (EFAS) yang penting dalam kolom faktor strategis. Penggunaan komponen internal yang digunakan adalah produksi, pendapatan, sumber daya manusia, manajemen dan pendanaan, pemasaran, didasarkan pada analisis rantai nilai korporasi dan untuk komponen eksternal yang digunakan adalah pesaing, pelanggan, iklim dan cuaca, teknologi, kebijakan pemerintah, yang didasarkan pada dua alat analisis 
lingkungan ekternal, yaitu analisis five forces dan analisis STEEPLE.

Quantitative Strategic Planning Matrix (QSPM), yaitu penentuan teknik keputusan dari kerangka kerja analisis formulasi strategi. Teknik ini secara jelas menunjukkan strategi alternatif mana yang paling baik untuk dipilih, menggunakan input dari hasil analisis (EFAS dan IFAS) dan pada pengolahan (matriks IE dan SWOT). Langkahlangkah penggunaan QSPM di dalam proses penetapan keputusan adalah membuat daftar peluang, ancaman, kekuatan, dan kelemahan agroindustri di kolom sebelah kiri QSPM, memberikan bobot pada masing-masing faktor eksternal dan internal, meneliti matriks-matriks pada langkah dua dan identifikasikan strategi alternatif yang pelaksanaannya harus dipertimbangkan, menentukan Attractiveness Score (AS) atau nilai daya tarik, menghitung jumlah AS, menghitung Sum Total Attractiveness Score (TAS) atau total nilai daya tarik (David 2004).

\section{HASIL DAN PEMBAHASAN}

\section{Karakteristik Konsumen Kerupuk Bawang}

Responden konsumen pada penelitian ini adalah konsumen yang mengonsumsi kerupuk bawang dari agroindustri KBWP. Rentang usia responden tertinggi berkisar antara 46 sampai dengan 52 tahun dengan status mayoritas konsumen telah menikah. Tingkat pendidikan konsumen kerupuk bawang tergolong tinggi yaitu SMA dan beberapa responden telah menempuh jenjang diploma dan sarjana. Jenis pekerjaan setiap konsumen beragam, ibu rumah tangga merupakan jenis pekerjaan terbanyak. Tingkat pendapatan konsumen pun beragam yaitu berkisar antara Rp1.000.000,00-Rp2.000.000,00 per bulan dengan jumlah anggota keluarga yang hanya berkisar 3-4 orang.

\section{Indeks Kepuasan Konsumen (Costumer Satisfaction Index)}

Pengukuran indeks kepuasan konsumen (CSI) dilakukan untuk menentukan sasaran-sasaran di masa yang akan datang dan mengetahui besarnya indeks kepuasan yang dihasilkan oleh suatu produk. CSI untuk atribut kerupuk bawang adalah sebesar 71,04 persen. Didasarkan pada indeks kepuasan, nilai CSI kerupuk bawang terletak pada rentang 0,66-0,80. Tabel 1 menunjukkan bahwa, secara umum indeks kepuasan konsumen kerupuk bawang berada pada kriteria "puas". Anggapan puas ini salah satunya disebabkan karena responden menganggap kerupuk bawang merupakan makanan yang sudah lama beredar di pasaran, dan juga kerupuk bawang sudah lama dikenal oleh masyarakat. Setiap waktu tingkat kepuasan konsumen dapat berubah, hal ini dapat terjadi tergantung dari tingkat kepentingan yang dibutuhkan oleh konsumen. Selain itu, promosi penjualan perlu ditingkatkan. Sebaiknya, agroindustri tidak hanya menggunakan metode mouth to mouth, tetapi dapat menggunakan media sosial, media cetak dan produk mampu dikenal masyarakat luar.

Penelitian ini sejalan dengan penelitian Pradita, Indriani, dan Soelaiman (2016) yaitu menyatakan bahwa nilai Customer Satisfaction Index (CSI) konsumen tauco di Kota Prabumulih adalah $71,20 \%$ sehingga konsumen berada pada kriteria puas. Penelitian ini juga sejalan dengan penelitian Sulfiana, Murniati, dan Indriani (2018) yang menyatakan bahwa nilai Customer Satisfaction Index (CSI) paket menu lele terbang di Rumah Makan Sambal Lalap di Bandar Lampung adalah 76,68 persen.

\section{Tingkat Loyalitas Konsumen}

Pada penelitian ini, loyalitas terhadap kerupuk bawang dinilai berdasarkan kriteria loyalitas yang terdiri dari alasan konsumen mengonsumsi kerupuk bawang, karena faktor harga (switcher buyer), faktor kebiasaan (habitual buyer), faktor kepuasan dalam konsumsi sebelumnya (satisfied buyer), konsumen benar-benar menyukai kerupuk bawang (liking the brand) dan merekomendasikan kerupuk bawang (committed buyer).

\section{a. Switcher Buyer}

Hal yang termasuk ke dalam tingkat switcher buyer adalah konsumen yang sensitif terhadap harga ataupun perubahan harga suatu produk. Hal ini menandakan bahwa konsumen tersebut tidak loyal atau tidak tertarik dengan merek tersebut. Switcher adalah responden yang menjawab pertanyaan yang tersedia dalam kuesioner dengan jawaban 'sering' dan 'sangat sering'. Hasil perhitungan didapatkan nilai switcher buyer sebesar 2,38 (rentang skala 2,60-3,39). Nilai ratarata diperoleh 6,67 persen sebanyak 4 orang responden. 


\section{b. Habitual Buyer}

Habitual buyer adalah responden yang membeli kerupuk bawang karena kebiasaan, sehingga tidak ada alasan yang kuat baginya untuk membeli merek produk lain yang membutuhkan pengorbanan seperti mengeluarkan biaya (switching cost). Responden yang membeli karena kebiasaan menjawab 'setuju' dan 'sangat setuju'. Sejak awal setelah melakukan pembelian, para konsumen sudah merasakan kepuasan tersendiri. Hal ini mengakibatkan mereka menjadi terbiasa untuk mengonsumsi kerupuk bawang dan akan kembali melakukan pembelian ulang terhadap produk kerupuk bawang tersebut, didapatkan nilai habitual buyer sebesar 3,58 (skala interval 3,40$4,19)$. Nilai rata-rata yang didapatkan 63,33 persen sebanyak 38 responden.

\section{c. Satisfied Buyer}

Satisfied buyer adalah responden yang masuk dalam kategori puas, bila mereka mengonsumsi kerupuk bawang. Meskipun demikian, mungkin saja mereka memindahkan pembeliannya ke produk lain dengan menanggung biaya peralihan (waktu, uang, atau kinerja). Hal ini berarti konsumen menemukan kepuasan dalam mengonsumsi produk kerupuk bawang. Satisfied buyer adalah responden yang menjawab 'puas' dan 'sangat puas'. Rata-rata responden yang merasa puas dengan produk kerupuk bawang ini ditunjukkan oleh nilai rata-ratanya sebesar 3,82 (skala interval 3,40-4,19) dengan nilai rata-rata sebesar 68,33 persen sebanyak 41 responden.

Responden yang menyatakan puas ini menyatakan bahwa kebutuhan mereka telah tercukupi. Agroindustri kerupuk bawang harus tetap menjaga dan mempertahankan nilai tersebut, karena tidak menutup kemungkinan konsumen bisa saja beralih ke merek lain.

\section{d. Liking The Brand}

Pembeli yang masuk dalam kategori liking the brand merupakan pembeli yang sungguh-sungguh menyukai kerupuk bawang. Responden yang benar-benar menyukai KBWP ini akan menjawab 'suka' dan 'sangat suka'. Nilai liking the brand yang didapatkan sebesar 3,80 (skala interval 3,40$4,19)$. Nilai rata-rata yang didapatkan sebesar 66,67 persen, artinya sebagian dari responden membeli kerupuk bawang, karena menyukai kerupuk tersebut dan memiliki pengalaman mengonsumsi kerupuk bawang, sehingga konsumen merasa terpenuhi kebutuhannya. Hal ini sangat baik bagi agroindustri KBWP, karena konsumen tergolong puas.

\section{e. Committed buyer}

Committed buyer adalah konsumen yang menjawab 'sering' dan 'selalu'. Golongan pembeli yang loyal terhadap kerupuk bawang sebanyak 41 responden. Rata-rata responden yang merasa puas terhadap produk kerupuk bawang ini ditunjukkan oleh nilai sebesar 3,62 (skala interval 3,40-4,19) dengan nilai rata-rata sebesar 68,33 persen, sebanyak 41 responden. Konsumen yang loyal terhadap produk KBWP ini merupakan konsumen yang loyal. Konsumen yang tergolong ke dalam commited buyer mengaku merasa percaya diri telah mengonsumsi kerupuk bawang dan bersedia untuk merekomendasikan produk kerupuk bawang kepada orang lain

Tabel 1. Perhitungan customer satisfaction indeks kerupuk bawang

\begin{tabular}{lcccc}
\hline \multicolumn{1}{c}{ Atribut } & $\begin{array}{c}\text { Rata-rata } \\
\text { Skor Kepentingan }\end{array}$ & $\begin{array}{c}\text { Weight } \\
\text { Factor }\end{array}$ & $\begin{array}{c}\text { Rata-rata } \\
\text { Skor Kinerja }\end{array}$ & $\begin{array}{c}\text { Weight } \\
\text { Score }\end{array}$ \\
\hline 1. Rasa & 4,12 & 0,12 & 4,00 & 0,48 \\
2. Harga & 3,98 & 0,12 & 3,95 & 0,46 \\
3. Ukuran kemasan & 3,68 & 0,11 & 3,52 & 0,37 \\
4. Tekstur & 3,92 & 0,11 & 3,88 & 0,44 \\
5. Kemudahan memperoleh produk & 3,93 & 0,11 & 3,93 & 0,45 \\
6. Warna & 3,55 & 0,10 & 3,42 & 0,35 \\
7. Bentuk & 3,58 & 0,10 & 3,48 & 0,36 \\
8. Aroma & 3,92 & 0,11 & 3,82 & 0,43 \\
9. Kandungan gizi & 3,88 & 0,11 & 1,90 & 0,21 \\
\hline Total skor & 34,57 & & & 3,55 \\
\hline \multicolumn{7}{c}{} \\
\hline
\end{tabular}


Tabel 2. Kerangka matrik faktor strategi internal untuk kekuatan dan kelemahan agroindustri KBWP

\begin{tabular}{|c|c|c|c|c|c|}
\hline & Faktor Eksternal & Bobot & Rating & Skor & Ranking \\
\hline A. & Kekuatan & & & & \\
\hline 1. & Kapasitas produksi besar. & 0,1059 & 4 & 0,4236 & 1 \\
\hline 2. & Usaha agroindustri kerupuk bawang menguntungkan. & 0,0947 & 3 & 0,2840 & 2 \\
\hline 3. & $\begin{array}{l}\text { Sudah dilakukan penerapan manajemen dan pencatatan } \\
\text { keuangan dengan baik. }\end{array}$ & 0,0897 & 3 & 0,2691 & 3 \\
\hline 4. & Jumlah sumber daya manusia agroindustri banyak. & 0,0885 & 2 & 0,1770 & 5 \\
\hline 5. & $\begin{array}{l}\text { Jumlah permintaan produk kerupuk bawang yang tinggi, } \\
\text { sehingga tanpa melakukan kegiatan promosi produk kerupuk } \\
\text { bawang tetap banyak dibeli oleh konsumen. }\end{array}$ & 0,0722 & 3 & 0,2167 & 4 \\
\hline B. & Kelemahan & & & & \\
\hline 1. & Kualitas produk kurang baik. & 0,0760 & 2 & 0,1521 & 5 \\
\hline 2. & Keuntungan usaha agroindustri yang berfluktuasi. & 0,1531 & 2 & 0,3061 & 3 \\
\hline 3. & $\begin{array}{l}\text { Belum diterapkannya secara tertulis pembukuan mengenai } \\
\text { pengeluaran dan penerimaan produk kerupuk bawang. }\end{array}$ & 0,1021 & 2 & 0,2042 & 4 \\
\hline 4. & $\begin{array}{l}\text { Sumber daya manusia yang dimiiki agroindustri belum } \\
\text { memiliki keterampilan yang baik. }\end{array}$ & 0,1032 & 3 & 0,3097 & 2 \\
\hline 5. & $\begin{array}{l}\text { Belum diterapkannya kegiatan promosi yang dapat } \\
\text { meningkatkan jumlah permintaan produk kerupuk bawang. }\end{array}$ & 0,1146 & 3 & 0,3438 & 1 \\
\hline
\end{tabular}

Lima tingkatan loyalitas konsumen ini digambarkan dalam piramida loyalitas yang dapat dilihat pada Gambar 1.

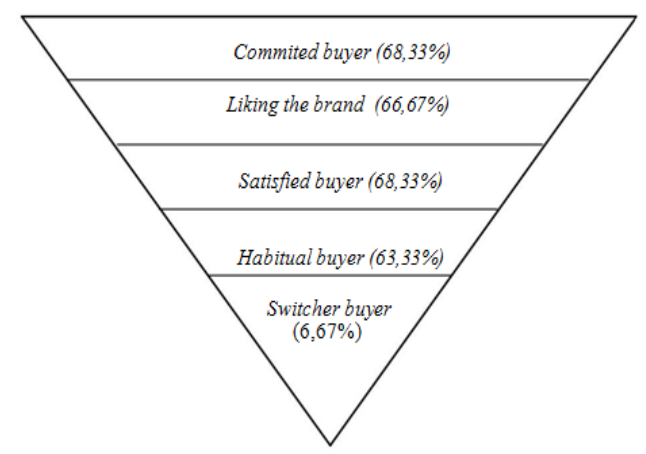

Gambar 1. Piramida loyalitas kerupuk bawang

Hasil penelitian ini berbeda dengan hasil penelitian yang dilakukan oleh Gadung, Zakaria, dan Murniati (2015) mengenai loyalitas konsumen kopi bubuk Sinar Baru Cap Bola Dunia menyatakan bahwa konsumen berada pada tingkatan loyalitas liking the brand dan hasil penelitian oleh Tunjungsari, Haryono, dan Lestari (2015) mengenai loyalitas konsumen dalam mengonsumsi santan Sun Kara di Bandar Lampung menyatakan bahwa konsumen berada pada tingkatan statisfied buyer.

\section{Strategi Pengembangan Agroindustri KBWP}

Tahap pengambilan strategi pengembangan adalah menganalisis faktor internal dan eksternal menggunakan analisis SWOT. Matriks internal kekuatan, kelemahan, dan juga matriks eksternal ancaman dan peluang dapat dilihat pada Tabel 2 dan 3. Analisis ini menggunakan matriks IE
(Internal dan Eksternal). Didapatkan nilai IFE sebesar 2,686 dan nilai EFE sebesar 2,465. Jika dipetakan dalam matriks IE, maka posisi agroindustri berada pada sel $\mathrm{V}$ dapat dilihat pada Gambar 2, yaitu pertumbuhan (growth). Artinya respon agroindustri KBWP terhadap faktor-faktor eksternal yang dihadapi tergolong sedang. Penggunaan matriks perencanaan strategis QSPM digunakan untuk menetapkan alternatif strategi tersebut secara objektif yang dapat dilihat pada Tabel 4. Strategi prioritas diurutkan berdasarkan total nilai daya tarik/total attractiveness score (TAS) tertinggi hingga terendah dari strategi alternatif yang sudah dipilih. Empat strategi prioritas utama dipilih pada penelitian ini. Penentuan bobot attractiveness score (AS) dilakukan dengan metode Focus Group Discussion (FGD).

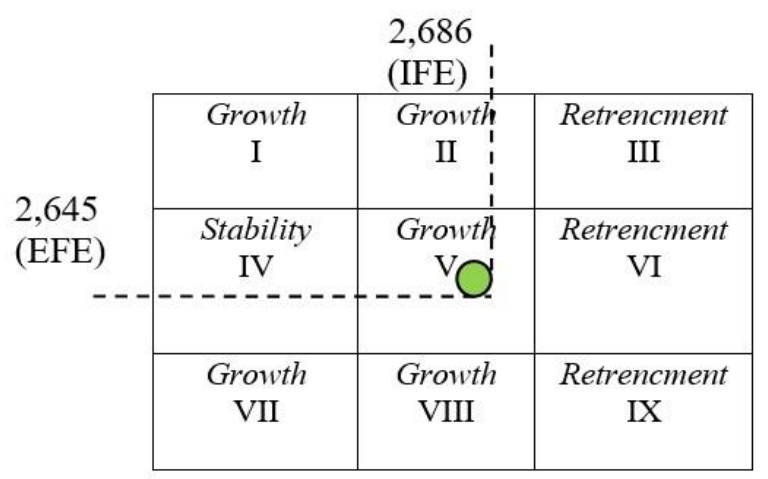

Gambar 2. Kuadran matriks internal dan eksternal 
Tabel 4. Matriks QSPM strategi pengembangan agroindustri KBWP

\begin{tabular}{|c|c|c|c|c|c|c|c|c|c|c|}
\hline \multirow{3}{*}{ Faktor utama } & & \multirow{3}{*}{ Bobot } & \multicolumn{8}{|c|}{ Alternatif Strategi } \\
\hline & & & \multicolumn{2}{|c|}{ Strategi 1} & \multicolumn{2}{|c|}{ Strategi 2} & \multicolumn{2}{|c|}{ Strategi 3} & \multicolumn{2}{|c|}{ Strategi 4} \\
\hline & & & AS1 & TAS1 & $\mathrm{AS} 2$ & TAS2 & AS3 & TAS3 & AS4 & TAS4 \\
\hline \multicolumn{11}{|l|}{ A. Faktor internal } \\
\hline \multirow[t]{5}{*}{ Kekuatan } & A & 0,105889 & 4 & 0,42356 & 4 & 0,42356 & 4 & 0,42356 & 3 & 0,31767 \\
\hline & B & 0,094661 & 3 & 0,28398 & 2 & 0,18932 & 3 & 0,28398 & 4 & 0,37864 \\
\hline & $\mathrm{C}$ & 0,089694 & 3 & 0,26908 & 3 & 0,26908 & 3 & 0,26908 & 3 & 0,26908 \\
\hline & $\mathrm{D}$ & 0,088488 & 4 & 0,35395 & 3 & 0,26546 & 2 & 0,17698 & 4 & 0,35395 \\
\hline & $\mathrm{E}$ & 0,072237 & 3 & 0,21671 & 4 & 0,28895 & 3 & 0,21671 & 3 & 0,21671 \\
\hline \multirow[t]{5}{*}{ Kelemahan } & $\mathrm{F}$ & 0,076041 & 3 & 0,22812 & 3 & 0,22812 & 3 & 0,22812 & 4 & 0,30417 \\
\hline & G & 0,153060 & 4 & 0,61224 & 3 & 0,45918 & 3 & 0,45918 & 3 & 0,45918 \\
\hline & $\mathrm{H}$ & 0,102096 & 3 & 0,30629 & 4 & 0,40838 & 4 & 0,40838 & 4 & 0,40838 \\
\hline & I & 0,103247 & 4 & 0,41299 & 3 & 0,30974 & 4 & 0,41299 & 2 & 0,20649 \\
\hline & $\mathrm{J}$ & 0,114587 & 4 & 0,45835 & 3 & 0,34376 & 3 & 0,34376 & 3 & 0,34376 \\
\hline \multicolumn{11}{|l|}{ B. Faktor eksternal } \\
\hline \multirow[t]{5}{*}{ Peluang } & A & 0,108499 & 4 & 0,43399 & 4 & 0,43399 & 4 & 0,43399 & 4 & 0,43399 \\
\hline & B & 0,091047 & 2 & 0,18209 & 3 & 0,27314 & 4 & 0,36419 & 3 & 0,27314 \\
\hline & $\mathrm{C}$ & 0,069849 & 4 & 0,27940 & 3 & 0,20955 & 3 & 0,20955 & 4 & 0,27940 \\
\hline & D & 0,103504 & 3 & 0,31051 & 4 & 0,41402 & 4 & 0,41402 & 3 & 0,31051 \\
\hline & $\mathrm{E}$ & 0,134662 & 2 & 0,26932 & 3 & 0,40399 & 3 & 0,40399 & 3 & 0,40399 \\
\hline \multirow[t]{6}{*}{ Ancaman } & F & 0,081059 & 3 & 0,24318 & 4 & 0,32423 & 3 & 0,24318 & 3 & 0,24318 \\
\hline & G & 0,071056 & 3 & 0,21317 & 3 & 0,21317 & 4 & 0,28422 & 3 & 0,21317 \\
\hline & $\mathrm{H}$ & 0,112273 & 4 & 0,44909 & 3 & 0,33682 & 3 & 0,33682 & 3 & 0,33682 \\
\hline & I & 0,105917 & 4 & 0,42367 & 3 & 0,31775 & 3 & 0,31775 & 2 & 0,21183 \\
\hline & $\mathrm{J}$ & 0,122135 & 2 & 0,24427 & 2 & 0,24427 & 2 & 0,24427 & 2 & 0,24427 \\
\hline & & & & 6,61400 & & 6,35600 & & 6,47500 & & 6,20800 \\
\hline
\end{tabular}

Terpilih urutan strategi pengembangan berdasarkan analisis QSPM adalah sebagai berikut:

1) Jumlah produksi kerupuk bawang mentah ditingkatkan terutama pada musim panas, agar tetap dapat memenuhi permintaan konsumen terhadap kerupuk bawang pada musim penghujan melalui penerapan alat mesin produksi yang lengkap dan telah dimiliki oleh agroindustri (6,614\%). Pengembangan Agroindustri KBWP menuju tahap yang lebih baik lagi dapat berupa peningkatan jumlah produksi kerupuk bawang. Permintaan akan kerupuk bawang yang tinggi menyebabkan agroindustri harus memproduksi lebih banyak lagi kerupuk bawang pada musim panas, agar dapat memenuhi permintaan kerupuk bawang pada musim penghujan. Produksi kerupuk bawang mentah melalui penerapan alat mesin produksi menjadi strategi alternatif yang dapat diterapkan oleh agroindustri. Pada musim penghujan, kerupuk bawang mentah digoreng untuk memenuhi permintan para konsumen, sehingga agroindustri tetap melakukan kegiatan produksi pada musim penghujan.

2) Menjaga dan meningkatkan produksi, sehingga konsumen tetap puas dan loyal terhadap produk kerupuk bawang $(6,475 \%)$. Konsumen merupakan faktor utama atau faktor paling penting dalam kegiatan usaha, banyak sedikitnya pelanggan dari suatu agroindustri dapat mempengaruhi tingkat keuntungan dari suatu agroindustri. Konsumen juga memiliki tingkat kepuasan dan kesetiaan yang berbeda terhadap produk, dimana tingkat kepuasan dan loyalitas dari konsumen ini harus ditingkatkan oleh Agroindustri KBWP. Jika konsumen yang dimiliki oleh Agroindustri KBWP merasa puas dengan produk kerupuk bawang, maka konsumen akan menjadi konsumen yang loyal terhadap produk KBWP ini.

3) Kegiatan promosi dilaksanakan meningkatkan permintaan produk yang hasilnya akan menciptakan keuntungan usaha yang semakin tinggi $(6,356 \%)$. Kegiatan promosi dalam Agroindustri KBWP belum diterapkan. Kegiatan promosi dapat dilakukan oleh agroindustri untuk menciptakan keuntungan usaha yang tinggi, promosi yang dilakukan dapat melalui sosial media. Penggunaan promosi melalui sosial media dapat mengenalkan produk kerupuk bawang kepada masyarakat yang belum mengetahui produk kerupuk bawang. Promosi yang dilakukan juga tidak terlepas dari inovasi-inovasi yang harus dilakukan, seperti menambahkan rasa-rasa pada kerupuk bawang, dan juga memperbaiki 
kemasan dari kerupuk bawang, agar lebih menarik dan dapat melindungi kerupuk bawang dari faktor luar yang dapat merubah atau merusak bentuk kerupuk bawang.

4) Mengikuti pembinaan yang dilakukan oleh Dinas Perindustrian di Kota Bandar Lampung (6,208\%). Dinas Perindustrian Kota Bandar Lampung memberikan bantuan berupa modal dan bantuan alat mesin produksi. Pembinaan yang dilakukan Dinas Perindustrian Kota Bandar Lampung dibutuhkan oleh agroindustri. Hal ini bertujuan agar produksi kerupuk bawang terjamin dapat terjual dan Agroindustri KBWP terus mengoptimalkan produksi kerupuk bawangnya. Selain itu, pembinaan ini juga membantu meringankan permodalan dan biaya alat-alat produksi, sehingga dapat mengurangi biaya agroindustri.

Penelitian Ariesta, Lestari, dan Sayekti (2016) terkait strategi pengembangan usaha agroindustri beras siger dirumuskan strategi yang dapat digunakan untuk pengembangan usaha yaitu meningkatkan modal kerja, agar dapat memenuhi permintaan produk beras siger dari konsumen yang tinggi yang dapat diperoleh dari dana pribadi maupun bantuan dari pemerintah melalui dinas dan instansi terkait. Berbeda dengan penelitian ini untuk strategi pengembangan pada Agroindustri KBWP, strategi yang terpilih merujuk kepada volume produksi, kepuasan, loyalitas konsumen, promosi, dan kerjasama dengan Dinas Perindustrian Kota Bandar Lampung.

\section{KESIMPULAN}

Konsumen KBWP berada pada kriteria puas. Konsumen KBWP adalah konsumen loyal. Strategi pengembangan yang diterapkan adalah jumlah produksi kerupuk bawang mentah ditingkatkan terutama pada musim panas, agar tetap dapat memenuhi permintaan konsumen terhadap kerupuk bawang pada musim penghujan, melalui penerapan alat mesin produksi yang lengkap dan telah dimiliki oleh agroindustri.

\section{DAFTAR PUSTAKA}

Ariesta W, Lestari DAH, dan Sayekti WD. 2016. Strategi pengembangan usaha Agroindustri
Beras Siger di Kota Bandar Lampung. JIIA,4(3):326-334.

http://jurnal.fp.unila.ac.id/index.php/JIA/articl e/view/1508. [24 Desember 2017].

BPS [Badan Pusat Statistik]. 2015. Produksi Ubi Kayu Menurut Provinsi. BPS. Jakarta.

David F. 2004. Manajemen Strategis : Konsepkonsep (Terjemahan). Indeks Gramedia. Jakarta.

Gadung A, Zakaria WA, dan Murniati K. 2015. Analisis kepuasan dan loyalitas konsumen Kopi Bubuk Sinar Baru Cap Bola Dunia di Kota Bandar Lampung. JIIA, 3(4): 370-376. http://jurnal.fp.unila.ac.id/index.php/

JIA/article/view/1086/991 _ [23 Desember 2017].

Pradita R, Indriani Y, dan Soelaiman A. 2016. Tingkat kepuasan dan loyalitas konsumen tauco di Kota Prabumulih. JIIA, 4(1) : 86-93. http://jurnal.fp.unila.ac.id/index.php/JIA/articl e/view/1218. [24 Desember 2017].

Rangkuti F. 2005. Analisis SWOT Teknik Membedah Kasus Bisnis. Gramedia Pustaka Utama. Jakarta.

Santoso S. 2006. Seri Solusi Berbasis TI Menggunakan SPSS dan Excel Untuk Mengukur Sikap dan Kepuasan Konsumen. PT Elex Media Komputindo. Jakarta.

Sulfiana WN, Murniati K, dan Indriani Y. 2018. Sikap dan kepuasan konsumen terhadap paket menu lele terbang, kaitannya dengan bauran pemasaran di Rumah Makan Sambal Lalap Bandar Lampung. JIIA, 6 (1) : 72-78. http://jurnal.fp.unila.ac.id/ index.php/JIA/article/view/2501/2185. Juli 2018].

Sufren dan Natanael Y. 2013. Mahir Menggunakan SPSS secara Otodidak. PT Elex Media Komputindo. Jakarta.

Supranto J. 2006. Pengukuran Tingkat Kepuasan Pelanggan Untuk Menaikkan Pangsa Pasar. Rineka Cipta. Jakarta.

Tunjungsari M, Haryono D, dan Lestari DAH. 2015. Kepuasan dan loyalitas konsumen ibu rumah tangga dalam mengonsumsi Santan Sun Kara di Kota Bandar Lampung. JIIA, 3 (3): 322-328. http://jurnal.fp.unila.ac.id/index.php/JIA/articl e/view/1058/963 . [11 Juli 2018]. 